\title{
ENDOGENOUS GROWTH MODELS: JONES VS ROMER THE PATH TO A FULLY-FLEDGED DYNAMIC ANALYSIS*
}

\author{
João Tovar Jalles†
}

October 2007

\begin{abstract}
The last two decades were marked by a high increase in economic growth research, namely related to three important issues as stated in Klenow et al. [1997]: world growth, country growth and dispersion in income levels.

The Charles Jones' [2002] technique to solve endogenous growth models relies on the two-step approach, which is in fact a clever way to study the dynamic behaviour of the usual two production factors of this type of models, technology and capital. However, he does that sequentially, therefore reducing the general scope of the model, as it is a special case of a broader version developed by David Romer [2001]. Romer's general case analyse the dynamic behaviour more closely and, more importantly, allowing for a simultaneous analysis of the dynamics of the endogenous factors, which provide additional insights. The aim of this paper is to tackle the differences between the two endogenous models as an exercise to see expost exogenous shocks' implications to the variables of interest. More specifically, in addition to the strictly theoretical analysis of some dynamic properties of the model, by programming difference equations in discrete time, one is also able to simulate and examine how the model will respond to shocks that one administer to it, on an ad-hoc basis - deterministic simulation.
\end{abstract}

JEL classification: 015, O30, O40, 041

Keywords: Solow Model, Endogenous Growth Models, Golden Rule

\footnotetext{
* I am grateful to Ana Balcão Reis and José Albuquerque Tavares for reading a preliminary version of this paper as well as for their helpful comments, suggestions and insights. The usual disclaimer applies, so that all remaining errors are mine alone.

† School of Economics, New University of Lisbon·Email: j.jalles@fe.unl.pt
} 


\section{$\underline{\text { Index }}$}

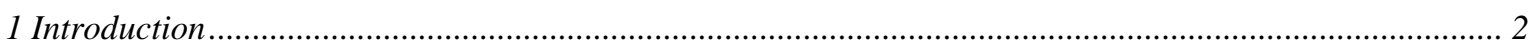

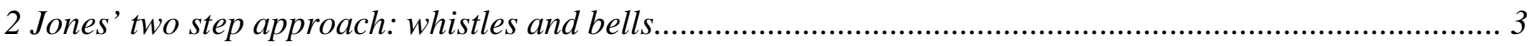

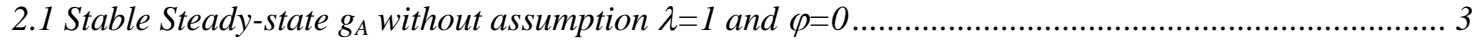

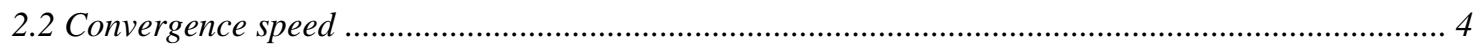

2.3 Steady-state income per head, $y^{*}(t)$, and its growth rate................................................................. 5

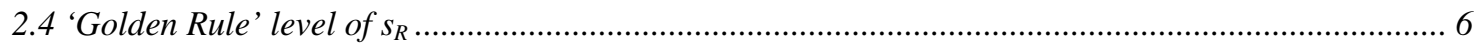

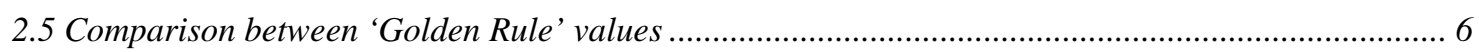

3 A full-fledged dynamic analysis......................................................................................................... 7

3.1 Growth Rates Derived ................................................................................................................. 7

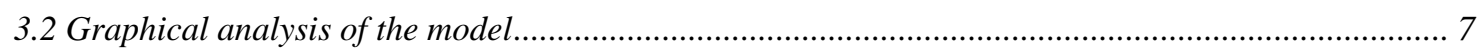

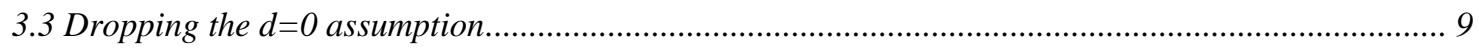

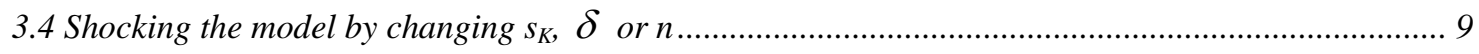

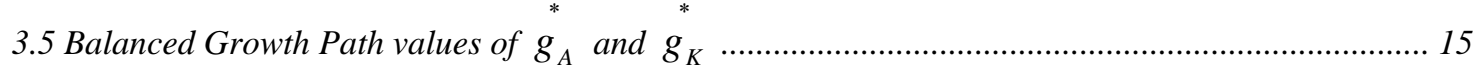

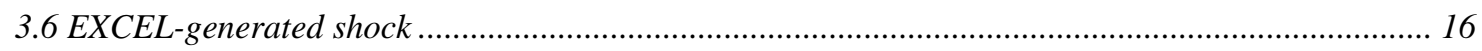

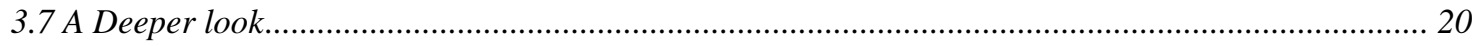

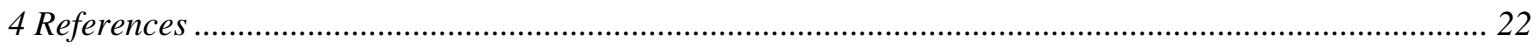




\section{Introduction}

The most well known models on endogenous growth belong the first group, i.e, "World Growth" as they often tend to explain the continuous rise in the growth of income per capita along time. Here the main references are undoubtedly, Lucas [1988], Romer [1990] and Grossman and Helpman [1991]. Over the last 200 years several countries have experienced sustained growth and that is why more recent research has been trying to account for this phenomenon. At an early stage models assumed positive rate of technological chance, but nowadays they have evolved to models that generate growth endogenously.

This paper is about the endogenous growth model discussed in Jones' [2002] section 5.1. This model is indeed very similar to the model presented in Romer's [2001] section 3.3, "The general case", apart from the fact that the accumulation of knowledge does not involve capital. This crucial factor allows Jones to perform a so called two-step analysis. His entire discussion of the dynamic properties of the model e the following sections of that chapter is based on this logic.

Starting with Jones' approach and in order to generalize the analysis, in the first section I will first relax his two restrictive assumptions, namely $\lambda=1$ and $\varphi=0$. Then I will study the implications of a shock in the technology steady state in terms of convergence speed and show that the new generalized version of the model implies that a steady-state income per head, and therefore consumption per head (naturally studying also the Golden Rule allocation), depends in an intricate way on the fraction of R\&D personnel, i.e, $s_{R}$.

Jones' two-step approach is a clever way to study the dynamic behaviour of the two endogenous production factors of his model (A and K) sequentially. But because the model is a special case of the endogenous growth model discussed in Romer section 3.3, one can examine its dynamic behaviour more closely using some tools. This allows for a simultaneous analysis of the dynamics of the endogenous factors, which will provide additional insights. Following Romer I omit depreciation and derive the equations for the growth rate of capital and technology, plotting them appropriately in a graphical space motivated by the arrows of motion. One important point in Romer's assumption is that he does not motivate this omission, but the implicit understanding is that this simplification will not fundamentally change the behaviour of the model. In fact, I will show that the same results applies with or without depreciation and observe what happens if the model is subject to shocks.

Finally, besides analyzing some dynamic properties of Jones' endogenous growth model mathematically (based on the standard formulation of the model in continuous time), a more interesting alternative way to examine these properties is to evaluate the model numerically, using a technique called deterministic simulation. This will require a reformulation of the model into discrete time, turning the differential equations into difference equations. Then one can simply program these difference equations and any other relevant model equations into EXCEL and examine how the model will respond to shocks that one can administer to it. 


\section{2) Jones' two step approach: whistles and bells}

\section{i) Stable Steady-state $g_{A}$ without assumption $\lambda=1$ and $\varphi=0$}

One can start with a simple model of endogenous growth described in the following way:

$Y=K^{\alpha}\left(A L_{Y}\right)^{1-\alpha}$ with $L_{Y}=\left(1-s_{R}\right) L$

$\dot{L}=n L$

$\dot{A}=\delta L_{A}^{\lambda} A^{\varphi}$ with $L_{A}=S_{R} L, \varphi<1,0 \leq \lambda \leq 1$

$\dot{K}=s_{K} Y-d K$

Contrarily to Jones' restrictive simplification, I will first show that the steady state for $\mathrm{g}_{\mathrm{A}}$ is stable without the extra assumptions that $\lambda=1$ and $\varphi=0$. Firstly, I show the derivation of the value for $\mathrm{g}_{\mathrm{A}}^{*}$, as this will also lead to the equation one needs in order to show the stability of the steady state without those assumptions. Given the underlying equations of the model, it follows:

$\frac{d A(t)}{d t}=\delta\left[\mathrm{s}_{\mathrm{R}} \mathrm{L}(\mathrm{t})\right] \mathrm{A}(\mathrm{t})^{\varphi} \quad$ and then divide by A to get,

$\mathrm{g}_{\mathrm{A}}(\mathrm{t})=\delta\left[\mathrm{s}_{\mathrm{R}} \mathrm{L}(\mathrm{t})\right]^{\lambda} \mathrm{A}(\mathrm{t})^{\varphi-1}$

Take $\operatorname{logs}$ and Derivatives w.r.t. $t$ and then multiply by $g_{A}$

$\dot{\mathrm{g}}_{\mathrm{A}}(\mathrm{t})=\lambda \mathrm{ng}_{\mathrm{A}}-(1-\varphi) \mathrm{g}_{\mathrm{A}}^{2}$

Given the still holding more general assumptions that $\varphi<1$ and $0 \leq \lambda \leq 1$, the term in brackets in front $\mathrm{g}_{\mathrm{A}}{ }^{2}$, (1- $\varphi$ ), is always positive becoming negative with the - sign in front of it. Thus, the equation for $\dot{\mathrm{g}}_{\mathrm{A}}(\mathrm{t})$ is a hill-shaped parabola in a $\left(\mathrm{g}_{\mathrm{A}}, \dot{\mathrm{g}}_{\mathrm{A}}\right)$-space. At the point where this phase diagram obeys the condition that $\dot{\mathrm{g}}_{\mathrm{A}}(\mathrm{t})=0$, we have the steady state. Thus:

$\lambda \mathrm{ng}_{\mathrm{A}}+(\varphi-1) \mathrm{g}_{\mathrm{A}}^{2}=0$

$\lambda \mathrm{n}=(1-\varphi) \mathrm{g}_{\mathrm{A}}$

$\mathrm{g}_{\mathrm{A}}^{*}=\frac{\lambda n}{1-\varphi}$

Thus it is derived the steady-state value for $g_{A}$. Now use the equation $\dot{g}_{A}(t)=\lambda \operatorname{ng}_{A}-(1-\varphi) g_{A}{ }^{2}$ to draw the phase diagram in order to show that this steady state is stable even without the assumptions $\lambda=1$ and $\varphi=0$. As a reminder, the assumptions that $\varphi<1$ and $0 \leq \lambda \leq 1$ remain. This gives us two different graphs, for the two cases where $\lambda=0$ or $0<\lambda \leq 1$. The specific value of $\varphi$ does not matter, as long as it is below 1 .

\section{CASE1: For $\lambda=0$ :}

In this case, the parabola is hill-shaped but because the first term, $\lambda_{\mathrm{n}} \mathrm{g}_{\mathrm{A}}$, drops out as a result of $\lambda=0$, it is not shifted and therefore its peak hits the $\mathrm{g}_{\mathrm{A}}$-axis at the origin. Nevertheless, we have a steady state at $(0 ; 0)$ that could have also been foreseen from the expression for $\mathrm{g}_{\mathrm{A}}{ }_{\text {, that }}$ thecomes zero when $\lambda=0$. The phase diagram depicting this situation is reproduced below. Assuming that $\mathrm{g}_{\mathrm{A}}$ is never below 0 , for any value above 0 , thus above the steady state, $\mathrm{g}_{\mathrm{A}}$ gets pulled back along the graph due to the negative $\dot{\mathrm{g}}_{\mathrm{A}}$ to the point where $\dot{\mathrm{g}}_{\mathrm{A}}$ is zero. 
Phase Diagram for $\lambda=0$

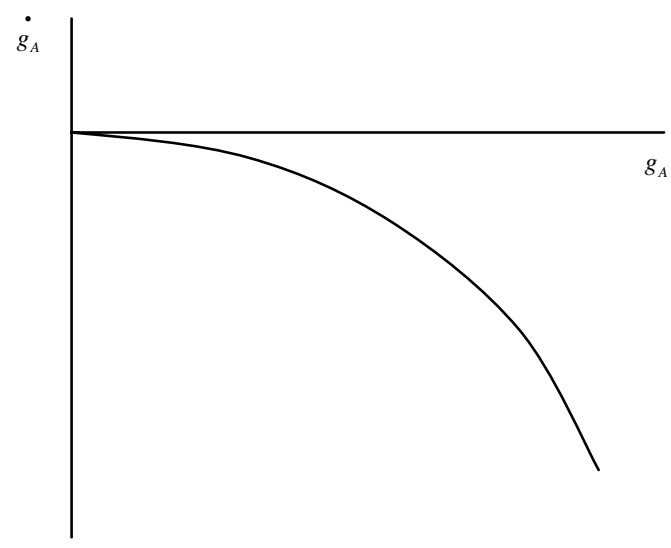

\section{CASE2: For $0<\lambda \leq 1$ :}

The first term of the $\dot{\mathrm{g}}_{\mathrm{A}}(\mathrm{t})$ now does not drop out anymore, but is positive, which causes the parabola to shift to the right and up. For small, positive values for $\mathrm{g}_{\mathrm{A}}, \dot{\mathrm{g}}_{\mathrm{A}}$ is positive and drags $\mathrm{g}_{\mathrm{A}}$ along the parabola graph to the right until $\mathrm{g}_{\mathrm{A}}$ reaches the value where it puts $\dot{\mathrm{g}}_{\mathrm{A}}$ equal to zero, thus its steady-state value. When $\mathrm{g}_{\mathrm{A}}$ is greater than its steady-state value, it gets pulled back along the graph back to the point where $\dot{\mathrm{g}}_{\mathrm{A}}$ equals zero.

Phase Diagram for $0<\lambda \leq 1$

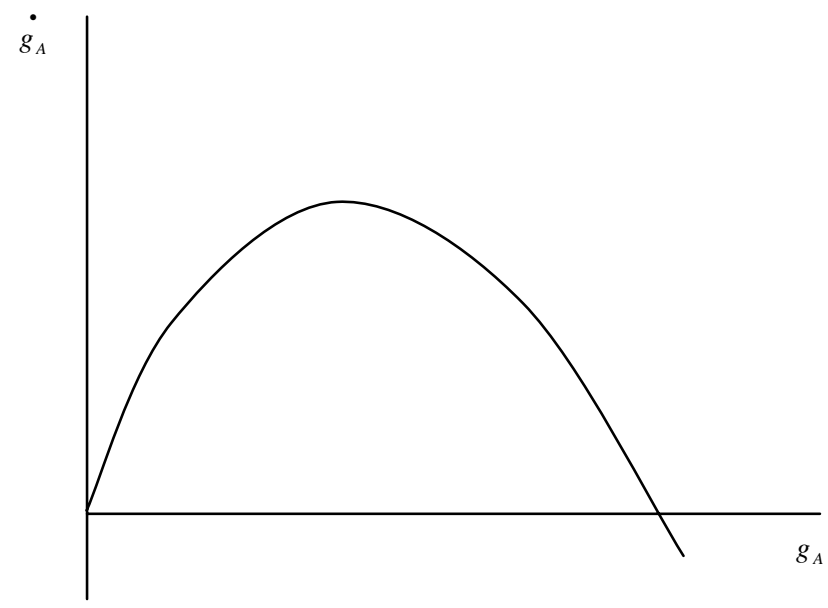

\section{ii) Convergence speed}

More interestingly, one can derive the convergence speed of this model by doing a first-order Taylor approximation of $\dot{\mathrm{g}}_{\mathrm{A}}(\mathrm{t})$ around $\mathrm{g}_{\mathrm{A}}=\mathrm{g}_{\mathrm{A}}{ }_{\mathrm{A}}$. This yields:

$\dot{g}_{A} \approx\left[\left.\frac{\partial \dot{g}_{A}\left(g_{A}\right)}{\partial g_{A}}\right|_{g_{A}=g_{A}}\right]\left(g_{A}-g_{A}{ }^{*}\right)$ 
Taking $\dot{\lambda}=-\left.\frac{\partial \dot{g}_{A}\left(g_{A}\right)}{\partial g_{A}}\right|_{g_{A}=g_{A}{ }^{*}}$ gives: $\dot{g}_{A}(t) \approx-\dot{\lambda}\left[g_{A}(t)-g_{A}{ }^{*}\right]^{\dagger}$

Integrating and thus going from $\dot{\mathrm{g}}_{\mathrm{A}}(\mathrm{t})$ to $\mathrm{g}_{\mathrm{A}}(\mathrm{t})$ one gets the following equation, relying on the fact that the system is stable. This stability was shown in the previous section, as $\mathrm{g}_{\mathrm{A}}$ converges to $\mathrm{g}_{\mathrm{A}}{ }_{\mathrm{A}}$.

$g_{A}(t) \approx g_{A}^{*}+e^{-\lambda t}\left[g_{A}(0)-g_{A}^{*}\right]$

Taking the expression for $\lambda$ stated above and differentiating equation $\dot{\mathrm{g}}_{\mathrm{A}}(\mathrm{t})=\lambda \operatorname{ng}_{\mathrm{A}^{-}}(1-\varphi) \mathrm{g}_{\mathrm{A}}{ }^{2}$ with respect to $\mathrm{g}_{\mathrm{A}}$, then plugging in $\mathrm{g}_{\mathrm{A}}^{*}=\frac{\lambda n}{1-\varphi}$ for $\mathrm{g}_{\mathrm{A}}$ yields:

$$
\begin{aligned}
\dot{\lambda} & =\left.\frac{\partial \dot{g_{A}}}{\partial g_{A}}\right|_{g_{A}=g_{A}}=-\left[\lambda n-2(1-\varphi) g_{A}{ }^{*}\right] \\
& =-\left[\lambda n-2(1-\varphi) \frac{\lambda n}{(1-\varphi)}\right]=-(-\lambda n)=\lambda n
\end{aligned}
$$

This gives a convergence speed of $\lambda \mathbf{n}$.

Assuming an arbitrary value for $\lambda$, say $\lambda=0.5$ and a population growth rate of $n=0.02$ gives a convergence speed of $\dot{\lambda}=0.5^{*} 0.02=0.01$. This yields a half-life value of the model of: $\ln (2) / \stackrel{i}{\approx} \approx 70$. So, ít takes approximately 70 years for the starting value of $g_{A}, g_{A}(0)$, to converge halfway to its steady-state value $\mathrm{g}_{\mathrm{A}}{ }_{\mathrm{A}}$. The convergence speed of $1 \%$ implied in this approach is small compared to the $4 \%$ convergence speed implied by the Solow model and also compared to the speed of $2 \%$ that is for instance defended by Sala-i-Martin [1996]. The 4\% convergence speed of the Solow model has been discussed in Romer's chapter 1.5 , yielding a half-life value for $\mathrm{k}$ and $\mathrm{y}$ to converge to their steady-state values $\mathrm{k}^{*}$ and $\mathrm{y}^{*}$ of roughly 18 years. The very long time of 70 years it takes for $g_{A}$ to converge to $\mathrm{g}_{\mathrm{A}}{ }_{\mathrm{A}}$ obviously depends on the choice of numerical values for the parameters $\lambda$ and $n$. Taking $\lambda=1$, which would be within the limits the model allows for, and leaving $n=0.02$ would give a convergence speed of $2 \%$ that is in accordance with Sala-i-Martin [1996] and empirical observance. The implied half life would be about 35 years. Summing things up, it seems that the convergence speed from $g_{A}$ to the balanced growth path at $g_{A}^{*}$ is simply slower than convergence that takes place from $\mathrm{k}$ to $\mathrm{k}^{*}$ or $\mathrm{y}$ to $\mathrm{y}^{*}$ as has been calculated for the Solow model.

\section{iii) Steady-state income per head, $y^{*}(t)$, and its growth rate}

In order to derive the generalized version of the Jones' model, dropping the assumptions that $\lambda=1$ and $\varphi=0$, one starts with the following equation from Jones $\left(\frac{Y}{A}\right)^{*}=\left(\frac{s_{K}}{n+g_{A}+d}\right)^{\frac{\alpha}{(1-\varphi)}}\left(1-s_{R}\right)$ and taking $\mathrm{L}_{\mathrm{A}}^{\lambda}=$ $\left(\mathrm{s}_{\mathrm{R}} \mathrm{L}\right)^{\lambda}$. Next, one solves the altered equation for $\mathrm{A}$ and plug it into the above equation, after it has been multiplied by A in order to get $\mathrm{y}^{*}$. This gives us the more interesting generalized version of the steadystate income per head. So,

\footnotetext{
${ }^{\dagger}$ I use the symbol $\grave{\lambda}$ to prevent confusion with the $\mathrm{L}_{\mathrm{A}}$-exponent in the defining equation of the model.
} 
$\frac{\dot{A}}{A}=\delta \frac{L_{A}{ }^{\lambda}}{A^{1-\varphi}}$ instead of $\dot{A}=\delta L_{A}$

$\Rightarrow L_{A}^{\lambda}=\left(s_{R} L\right)^{\lambda}$

Solving the altered formula for $\mathrm{A}$

$\frac{\dot{A}}{A}=\delta \frac{\left(s_{R} L\right)^{\lambda}}{A^{1-\varphi}} \Rightarrow A=\left(\frac{\delta\left(s_{R} L\right)^{\lambda}}{g_{A}}\right)^{\frac{1}{(1-\varphi)}}$

and plug A into Jones' equation described above, after it has been multiplied by A in order to get $\mathrm{y}^{*}$.

$y^{*}(t)=\left(\frac{s_{K}}{n+g_{A}+d}\right)^{\frac{\alpha}{(1-\alpha)}}\left(1-s_{R}\right)\left[\frac{\delta\left(s_{R} L\right)^{\lambda}}{g_{A}}\right]^{\frac{1}{1-\varphi}}$

The growth rate can be obtained by taking logs and derivatives of the generalized version.

$$
\begin{aligned}
& \ln y^{*}(t)=\frac{\alpha}{(1-\alpha)}\left(\ln s_{K}-\ln \left(n+g_{A}+d\right)\right)+\ln \left(1-s_{R}\right)+\frac{1}{(1-\varphi)}\left[\ln \delta+\lambda \ln s_{R}+\lambda \ln L-\ln g_{A}\right] \\
& \frac{d \ln y^{*}(t)}{d(t)}=\frac{1}{(1-\varphi)} \lambda g_{L} \Rightarrow g_{A}=\frac{\lambda n}{1-\varphi}
\end{aligned}
$$

\section{iv) ‘Golden Rule’ level of $s_{R}$}

In order to maximize steady-state consumption per head, we maximized steady-state income per head. This is possible as consumption is defined as a constant fraction (1-s) of income. Differentiate the formula derived in part iii) with respect to $\mathrm{s}_{\mathrm{R}}$. This was put equal to zero and solved for $\mathrm{s}_{\mathrm{R}}$. The resulting expression represents the 'Golden Rule' level of $\mathrm{s}_{\mathrm{R}}$ that maximizes steady-state income per head, and therefore also steady-state consumption per head.

$y^{*}(t)=\left(\frac{s \stackrel{*}{K}}{n+\dot{g}^{*} A+d}\right)^{\frac{\alpha}{(1-\alpha)}}\left(1-s_{R}\right)\left[\frac{\delta\left(s_{R} L\right)^{\lambda}}{\dot{g}_{A}^{*}}\right]^{\frac{1}{(1-\varphi)}}$

Maximization by taking the derivative with respect to $\mathrm{s}_{\mathrm{R}}$

$$
\frac{d y^{*}(t)}{d\left(s_{R}\right)}=\left(\frac{s_{K}}{n+g_{A}+d}\right)^{\frac{\alpha}{(1-\alpha)}}\left(\frac{\delta L^{\lambda}}{g_{A}}\right)^{\frac{1}{(1-\varphi)}} \frac{\lambda}{(1-\varphi)} s_{R}^{\left(\frac{\lambda}{1-\varphi}-1\right)}-\left(\frac{s_{K}}{n+g_{A}+d}\right)^{\frac{\alpha}{(1-\alpha)}}\left(\frac{\delta L^{\lambda}}{g_{A}}\right)^{\frac{1}{(1-\varphi)}}\left[\left(\frac{\lambda}{1-\varphi}\right)+1\right] s_{R}^{\frac{\lambda}{(1-\varphi)}}
$$

After canceling out, setting the derivative equal to zero and solving for $\mathrm{s}_{\mathrm{R}}$ the following results can be obtained:

$$
\frac{d y^{*}(t)}{d\left(s_{R}\right)}=0 \Rightarrow \frac{\lambda}{(1-\varphi)} s_{R}\left(\frac{\lambda}{1-\varphi}-1\right)=\left(\frac{\lambda}{1-\varphi}+1\right) s_{R}^{\frac{\lambda}{(1-\varphi)}} \Rightarrow \quad>\quad \frac{\frac{\lambda+1-\varphi}{1-\varphi}}{s_{R}^{-1}=>} s_{R}=\frac{1}{1+\left(\frac{1-\varphi}{\lambda}\right)}
$$

\section{v) Comparison between 'Golden Rule’ values}

I show that the 'Golden Rule' value for $\mathrm{s}_{\mathrm{R}}$ that was derived in the previous section is almost certainly higher then the 'Golden Rule' value produced by the free market given by Jones' analogous equation $s_{R}=\frac{1}{1+\frac{r-n}{\alpha g_{A}}}$ ('Golden Rule' value produced by the free market - in fact it corresponds to Jones' eq. (5.19)). 
I replaced $g_{A}$ by its steady-state value $g_{A}{ }^{*}=\frac{\lambda n}{1-\varphi}$. In order to show that my value is higher than Jones' one, one needs to compare the fractions within the denominator as they constitute the only difference between the equations.

$\frac{r-n}{\alpha} * \frac{1-\varphi}{\lambda n}>\frac{1-\varphi}{\lambda}$

Cancelling several terms, the following result can be obtained, $\frac{r-n}{\alpha n}>1$

Presuming values of $r=0.04, n=0.02$ and $\alpha=1 / 3$, one gets

$\frac{0.04-0.02}{1 / 3 * 0.02}>1 \quad \Rightarrow \quad 3>1$

This shows that the 'Golden Rule' value derived in section iv) is indeed most probably higher than the value found by Jones.

\section{3) A full-fledged dynamic analysis}

\section{i) Growth rates derived}

In order to bridge Jones' analysis to Romer's one is required to derive the equations for $g_{A}(t), g_{A}(t), g_{K}(t)$ and $g_{K}(t)$ accordingly. From part A i) one already knows $g_{A}(t)$ and $g_{A}(t)$ :

$\mathrm{g}_{\mathrm{A}}(\mathrm{t})=\delta\left[\mathrm{s}_{\mathrm{R}} \mathrm{L}(\mathrm{t})\right]^{\lambda} \mathrm{A}(\mathrm{t})^{\varphi-1}$

$\operatorname{gg}_{\mathrm{A}}(\mathrm{t})=\lambda \mathrm{n}-(1-\varphi) \mathrm{g}_{\mathrm{A}}$

$\dot{\mathrm{g}}_{\mathrm{A}}(\mathrm{t})=\lambda \mathrm{ng}_{\mathrm{A}}-(1-\varphi) \mathrm{g}_{\mathrm{A}}^{2}$

$\mathrm{g}_{\mathrm{A}}^{*}=\frac{\lambda n}{1-\varphi}$

All that is left to do is derive $g_{K}(t)$ and $g_{K}(t)$ under the assumption that $d=0$, after substituting $Y$ and $L_{Y}$ we get:

$\dot{K}=s_{K} K^{\alpha}\left(A L_{Y}\right)^{1-\alpha}=s_{K} K^{\alpha}\left[A\left(1-s_{R}\right) L\right]^{1-\alpha} \quad$ Divide by $\mathrm{K}$

$g_{K}=s_{K} \frac{\left[A\left(1-s_{R}\right) L\right]^{1-\alpha}}{K}$

Take logs and derivatives w.r.t. $\mathrm{t} g g_{K}=(1-\alpha)\left(g_{\mathrm{A}}+n-g_{K}\right)$ and multiplying with $\mathrm{g}_{\mathrm{K}}$, it yields,

$\dot{g_{K}}=(1-\alpha)\left(g_{A}+n-g_{K}\right) g_{K} \Rightarrow \stackrel{*}{*}_{K}=g_{A}+n$

\section{ii) Graphical analysis of the model}

In the following part we will construct a graphical representation of the equations from part i), starting with representing $\dot{g}_{K}=0$ in $\left(\mathrm{g}_{\mathrm{K}} . \mathrm{g}_{\mathrm{A}}\right)$ space: 


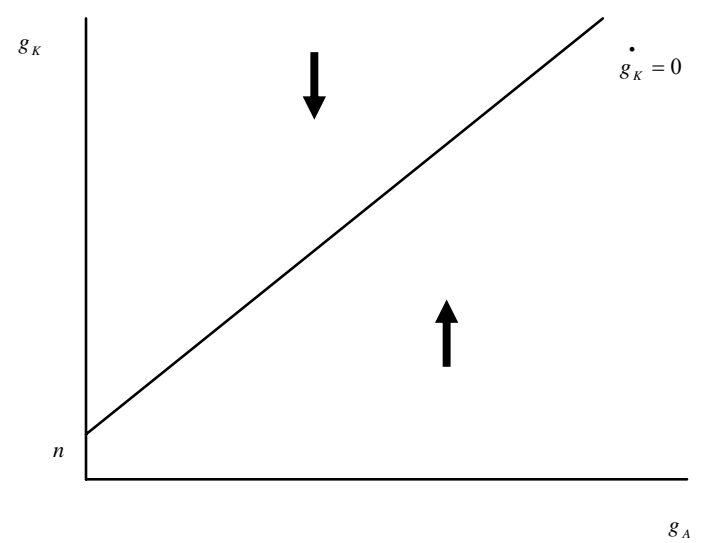

the $\dot{g_{K}}=0$ line has a slope equal to one as can be derived from the equations above. Also we should note that values of $\mathrm{g}_{\mathrm{K}}$ that lie above the $\dot{g}_{K}=0$ line will result in a negative $\dot{g}_{K}$ and thus a movement towards the Balanced Growth Path (BGP) line, below the line $\mathrm{g}_{\mathrm{K}}$ will be pulled up. Another interesting feature of the model is the intersection with the $g_{K}$ axes at $n$.

When one looks at $\dot{g}_{A}=0$ the following picture emerges:

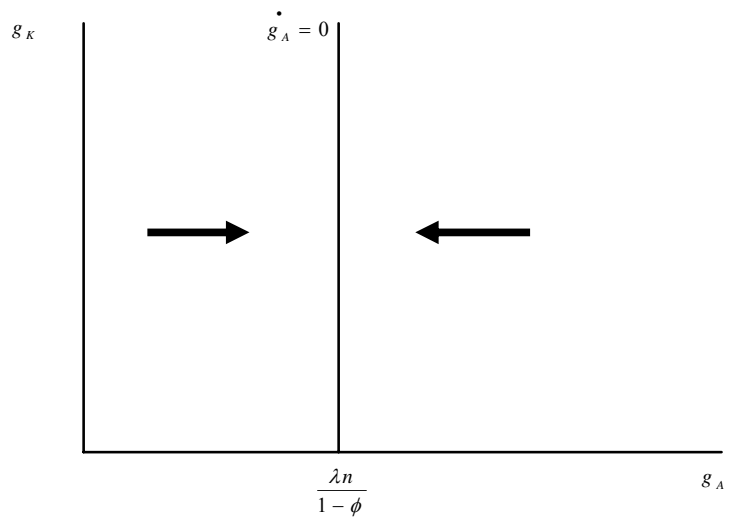

As can be read from the $\dot{g}_{A}=0$ equation it does not depend on $g_{K}$ and is thus a vertical line. When one puts $\dot{g}_{A}=0$ one is able to find that the solution for $\mathrm{g}_{\mathrm{A}}$ to this equation is always $\frac{\lambda n}{1-\varphi}$. A $\mathrm{g}_{\mathrm{A}}$ lower then $\frac{\lambda n}{1-\varphi}$ ( $\mathrm{g}_{\mathrm{A}}$ is to the left of the $\dot{g}_{\mathrm{A}}=0$ line) would mean it is increasing towards $\frac{\lambda n}{1-\varphi}$ and above decreasing towards it, as illustrated by the arrows.

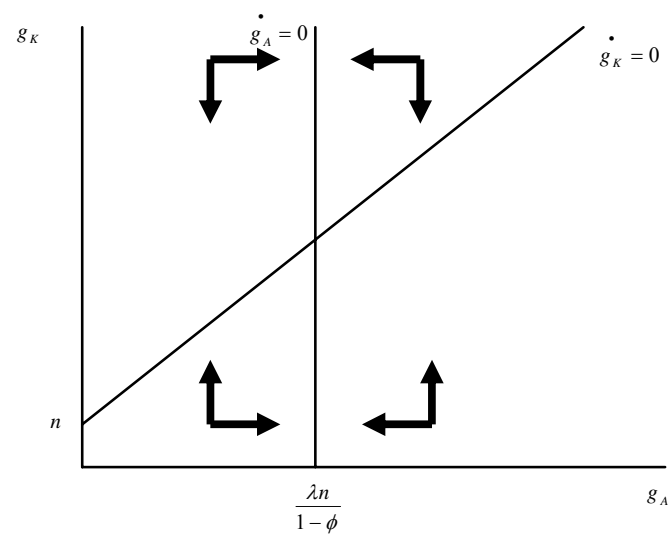


Now if I combine both schedules we get the full picture: Here one has the full dynamic picture of the model. Also noteworthy would be the meaning of the $\dot{g}_{A}=0$ line. It is vertical due to the independence from $\mathrm{g}_{\mathrm{K}}$, as said before, and this allows for the so called "two-step approach", allowing to solve for $\mathrm{g}_{\mathrm{A}}$ first and then for $\mathrm{g}_{\mathrm{K}}$. Once at the BGP one will have a $\mathrm{g}_{\mathrm{A}}$ and $\mathrm{g}_{\mathrm{K}}$ of $\frac{\lambda n}{1-\varphi}$ and $\frac{\lambda n}{1-\varphi}+\mathrm{n}$ respectively.

\section{iii) Dropping the $\mathrm{d}=\mathbf{0}$ assumption}

In the previous 2 parts I explicitly excluded depreciation from the calculation, but now I will come back to this assumption and will show that it is actually an assumption that only simplifies derivations but does not really affect the outcome of the model in the end. First I derive the same things as in point i) with depreciation.

$\dot{K}=s_{K} K^{\alpha}\left(A L_{Y}\right)^{1-\alpha}-d K=s_{K} K^{\alpha}\left[A\left(1-s_{R}\right) L\right]^{1-\alpha}-d K \quad$ Dividing by $\mathrm{K}$ and adding $\mathrm{d}$ to both sides, it yields, $g_{K}+d=s_{K} \frac{\left[A\left(1-s_{R}\right) L\right]^{1-\alpha}}{K}$

Taking logs and derivatives w.r.t. $\mathrm{t}$ one gets $g g_{K+d}=(1-\alpha)\left(g_{\mathrm{A}}+n-g_{K}\right)$

Unfortunately this result gives something one can not work with, however if I transform this equation into

a $\dot{g_{K}}+\dot{d}$ format by multiplying the previous formula by $g_{K}+d$ one gets the following

$$
\dot{g}_{K}+\dot{d}=(1-\alpha)\left(g_{A}+n+g_{K}\right)\left(g_{k}+d\right) \quad \text { noting } \dot{d}=0
$$

$\dot{g_{K}}=(1-\alpha)\left(g_{A}+n+g_{K}\right)\left(g_{k}+d\right) \quad$ solving for steady state

$\stackrel{*}{g_{K}}=g_{A}+n$

So, even if one includes $d$ in the model in the end it does not change the value for $g_{K}$ in the end, and so the growth of $\mathrm{K}$ is not altered nor is that of $\mathrm{A}$ at the Balanced Growth Path, concluding that the assumption of $\mathrm{d}=0$ can be dropped without harming the analysis.

\section{iv) Shocking the model by changing $\mathrm{s}_{\mathrm{K}} \delta$ or $\mathrm{n}$}

In this section I will implement certain shocks to the model to see what the effects will be in each of the cases. Consider permanent increases in the following exogenous variables: $\mathrm{s}_{\mathrm{K}}, \delta$ and $\mathrm{n}$.

What do these permanent increases change about the position of our $\dot{g}_{A}=0$ and $\dot{g}_{K}=0$ lines? When one looks at the equations for $\dot{g}_{A}$ and $\dot{g}_{K}$ we will notice that neither depends on $\mathrm{s}_{\mathrm{K}}$ nor $\delta$. Therefore no matter what happens to these variables the lines do not move in anyway, indicating that in the long run the growth rates can not be influenced by these level variables. However one does see both equations depending on $\mathrm{n}$ positively, so in the case of an increase in $\mathrm{n}$ changes in the long run behaviour of the model will take place, as represented below. 


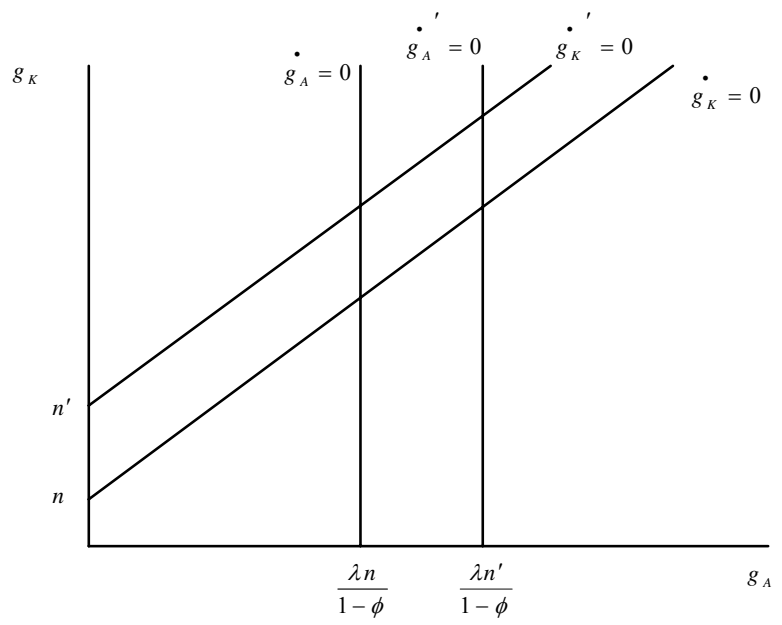

Even though not every shock changes the long run equilibrium there might be immediate changes in the position of the economy after a shock. Looking at the model I will notice that the value of $g_{K}$ does depend on $\mathrm{s}_{\mathrm{K}}$ and also that $g_{\mathrm{A}}$ does depend on $\delta$, however neither depends on $\mathrm{n}$, meaning that directly after the increase in $\mathrm{n}$ the economy is still stuck at the old equilibrium.

Now we show what happens when $\mathrm{s}_{\mathrm{K}}$ increases in $\left(g_{A}, g_{K}\right)$-space.

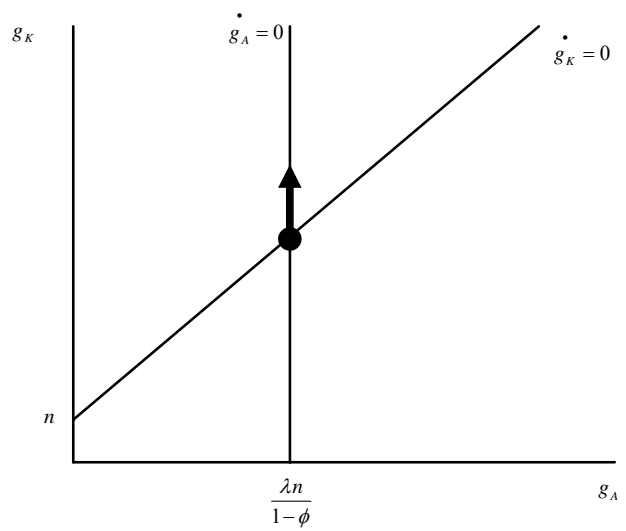

The economy will incur an increase in $g_{K}$ at the instant $\mathrm{s}_{\mathrm{K}}$ increases, thus moving the economy above its BGP value of $g_{K}$. When one permanently increases $\delta$ the following will happen to this economy. 


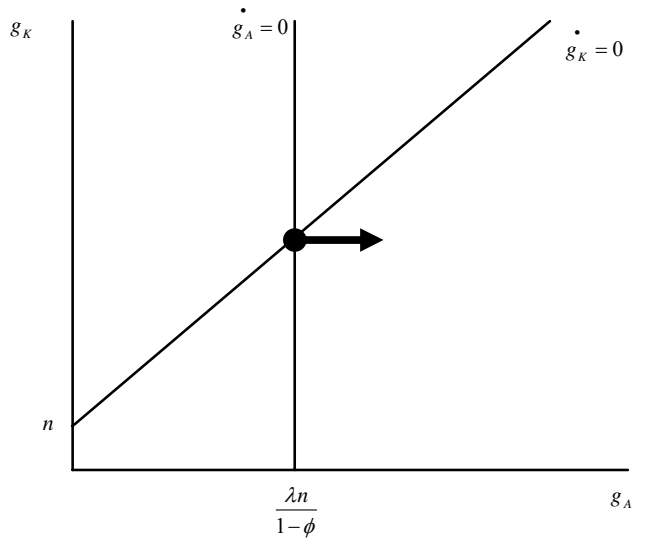

An immediate increase in $g_{A}$ is what one gets after the permanent increase in $\delta$, leading to point to the right of the Balanced Growth Path. Combining what I have seen in the previous discussion I now know where the economy will go to and where it is after the shocks occur. Combining the 2 phases one can now discuss the transition dynamics that will develop as time passes.

$g_{K}$ will move quickly towards the equilibrium, along the $\dot{g}_{A}=0$ line, in the first years. However as time passes its descent goes slower and slower and it will only return to its Balanced Growth Path in the limit.

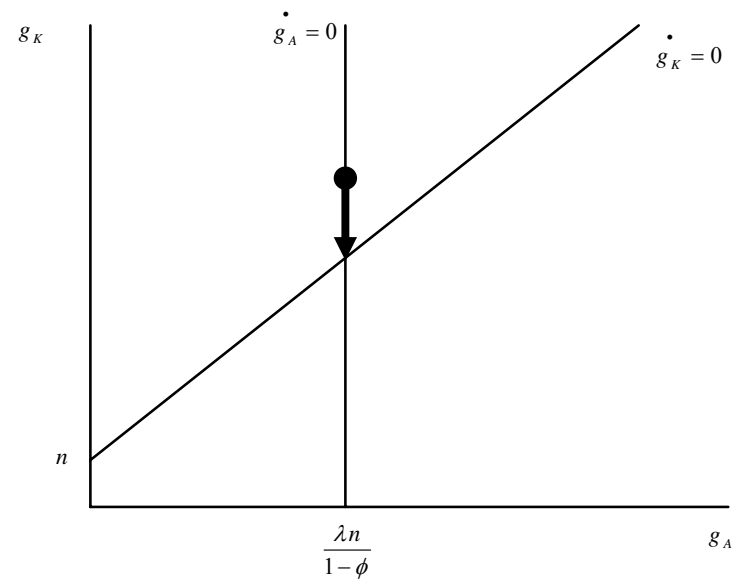

Unlike with the value of $g_{K}$, a change in $g_{A}$ does not only affect future values of $g_{A}$ but also future values of $g_{K}$. An increase in $g_{A}$ will trigger an increase in $g_{K}$ over time as it also triggers a decrease in $g_{A}$. As time passes and $g_{A}$ comes closer to its BGP value $g_{K}$ will also start to decline again, that is, after it passes through the $\dot{g}_{K}=0$ line.

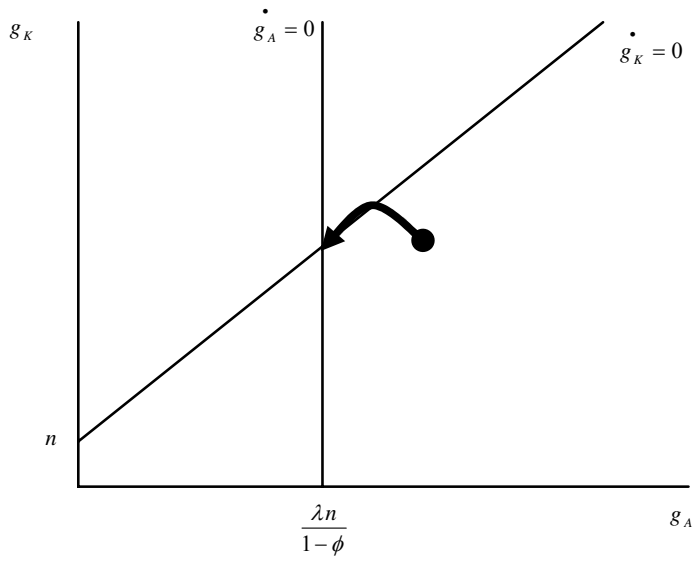


With the increase in $\mathrm{n}$ one starts out in the old BGP situation, since the economy's growth rates for $\mathrm{g}_{\mathrm{A}}$ and $g_{K}$ only change after $L$ has started to increase. The adjustment will be linear from the old to the new BGP as shown below.

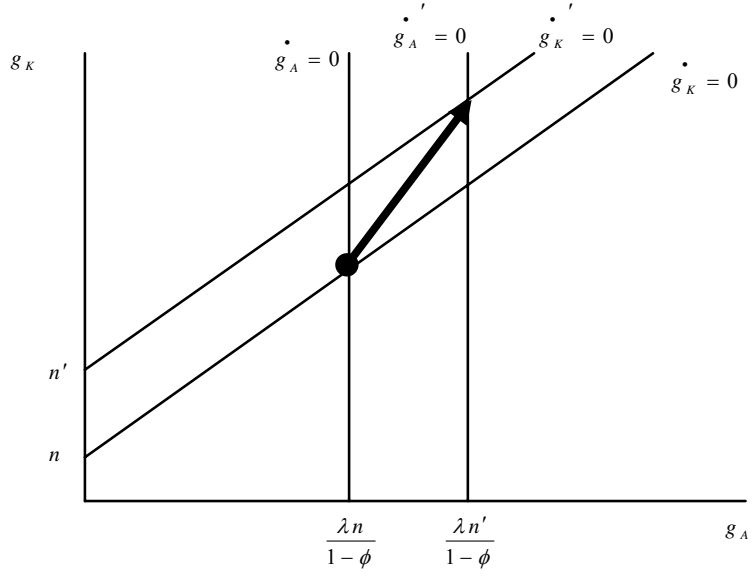

Now one turns to see what the affect of the shocks are on the values of $\ln$ A over time. Since A does not depend on the value of $s_{K}$ in any way, permanently increasing it does not affect A. But that is not the case when one considers a permanent increase in $n$, in this case one does see a change in $g_{A}$. I know from the previous discussion that the growth rate of A does not change in the long run, only in the short run will we see a higher $g_{A}$. This indicates a level affect on $\ln A$ due to the permanent increase in $s_{K}$ as shown below assuming a shock at $\mathrm{t}(0)$.

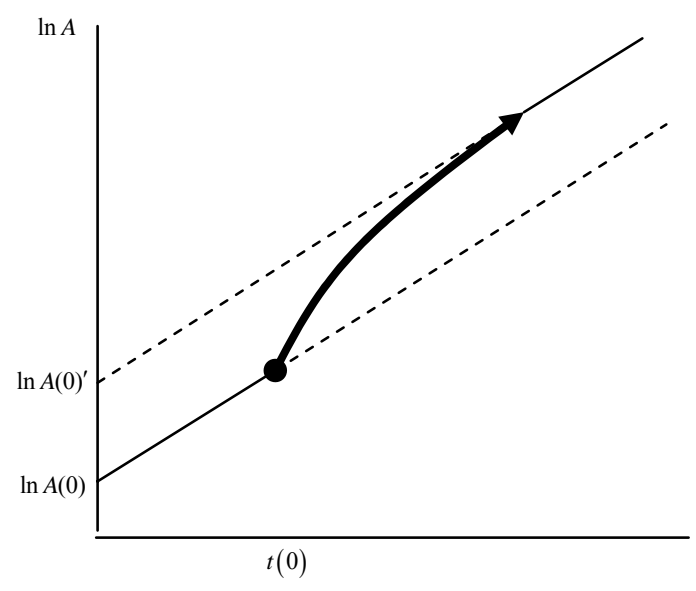

Finally, I will discuss the affect of an increase in $\mathrm{n}$ on $\ln$ A. Previously I have seen that I will arrive at a higher BGP in the long run, also I know the way it will move towards this new BGP. So, ln A will reach a new and higher growth path when $\mathrm{n}$ permanently increases, meaning that the $\ln \mathrm{A}$ line will become steeper and will eventually reach this new slope after slowly adjusting to it from the time that $\mathrm{n}$ has increased as is shown in the graph below. 


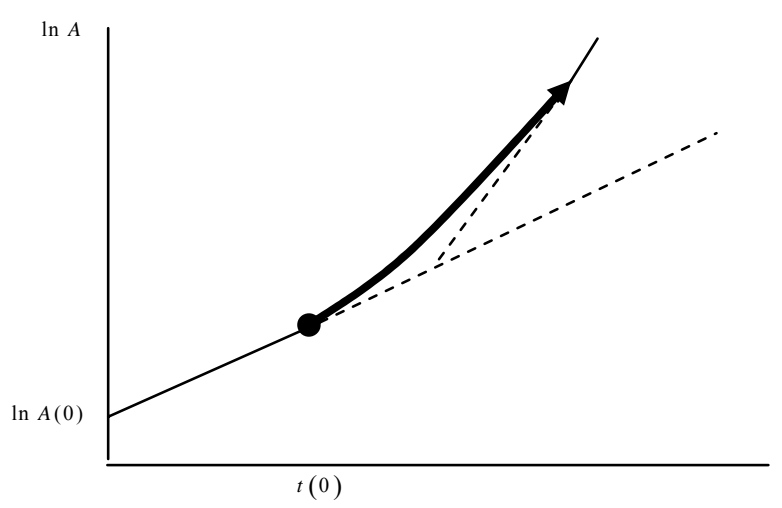

I am now ready to discuss what happens to income per head during the 3 specific shocks, first it is necessary to find the expression for $\frac{Y}{L}$, using the normal production function we find the expression for $\ln \left(\frac{Y}{L}\right)$ $\frac{Y}{L}=\frac{K^{\alpha}\left[A\left(1-s_{R}\right)\right]^{1-\alpha}}{L^{\alpha}} \Rightarrow>\ln \left(\frac{Y}{L}\right)=\alpha \ln K+(1-\alpha) \ln \left(A+1-s_{R}\right)-\alpha \ln L$

Now that one knows the way $\ln \left(\frac{Y}{L}\right)$ moves, it can be seen that an increase in $\mathrm{S}_{\mathrm{K}}$, which increases $\mathrm{g}_{\mathrm{K}}$ will increase the slope of $\ln \left(\frac{Y}{L}\right)$, through $\mathrm{K}$, but as soon as the transition affect wears off $\ln \left(\frac{Y}{L}\right)$ will have the same slope as before and only a level effect has resulted from the increase in $\mathrm{s}_{\mathrm{K}}$.

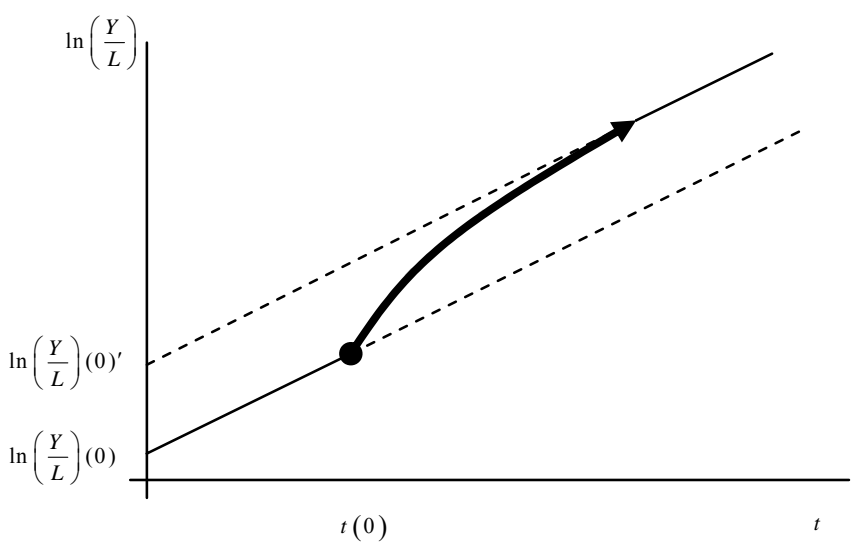

In the end I will see the same thing for the increase in $\delta$ as I saw with the increase in $\mathrm{s}_{\mathrm{R}}$ but there are differences. In the case of a permanent increase in $\delta$ I do not just have a higher $\mathrm{g}_{\mathrm{A}}$ but I also get a higher $\mathrm{g}_{\mathrm{K}}$. Depending on the magnitude of the parameters $\ln \left(\frac{Y}{L}\right)$ might end up at a higher level then with the increase in $s_{R}$ or a lower level.

The permanent increase in $\mathrm{n}$ is trickier to analyze than the previous shocks. In order to see the affect of the increase in $\mathrm{n}$ I first derive the growth rate of income per head by differentiating the formula for $\ln \left(\frac{Y}{L}\right)$ w.r.t. t. $g_{\left(\frac{Y}{L}\right)}=\alpha g_{K}+(1-\alpha) g_{A}-\alpha n$ 
At this point one needs to combine all the previous results to see what will happen to $\ln \left(\frac{Y}{L}\right)$ when I increase $\mathrm{n}$. First of all it can be seen from the equation above that as soon as the population growth rate increases the growth rate of income per head falls. One has seen previously that an increase in population growth will increase $g_{A}$ over time together with $g_{K}$. Looking back at the formula for $g_{A}$ we find that due to the population increase we will have a new $g_{A}^{*}$ at $g_{A}^{*}=\frac{\lambda n}{1-\varphi}$ combining this with the formula $g_{K}^{*}$ we find $g_{K}^{*}=\frac{\lambda n}{1-\varphi}+n$.

From the formula for $g_{\left(\frac{y}{L}\right)}$ I find that there will be a BGP equal to $\frac{\lambda n}{1-\varphi}$, which follows from plugging the values for $g_{K}^{*}$ and $g_{A}^{*}: g_{\left(\frac{Y}{L}\right)}^{*}=\alpha g_{K}^{*}+(1-\alpha) g_{A}^{*}-\alpha n$ $g_{\left(\frac{Y}{L}\right)}^{*}=\alpha\left(\frac{\lambda n}{1-\varphi}+n\right)+(1-\alpha) \frac{\lambda n}{1-\varphi}-\alpha n=\alpha n+\frac{\lambda n}{1-\varphi}-\alpha n=\frac{\lambda n}{1-\varphi}$

After all the dynamics have been worked out in both $g_{A}$ and $g_{K}$ an increase in $n$ will always create a faster growth in income per head all other things constant, however only after an initial drop in the growth rate of income per head. I will now illustrate this below.
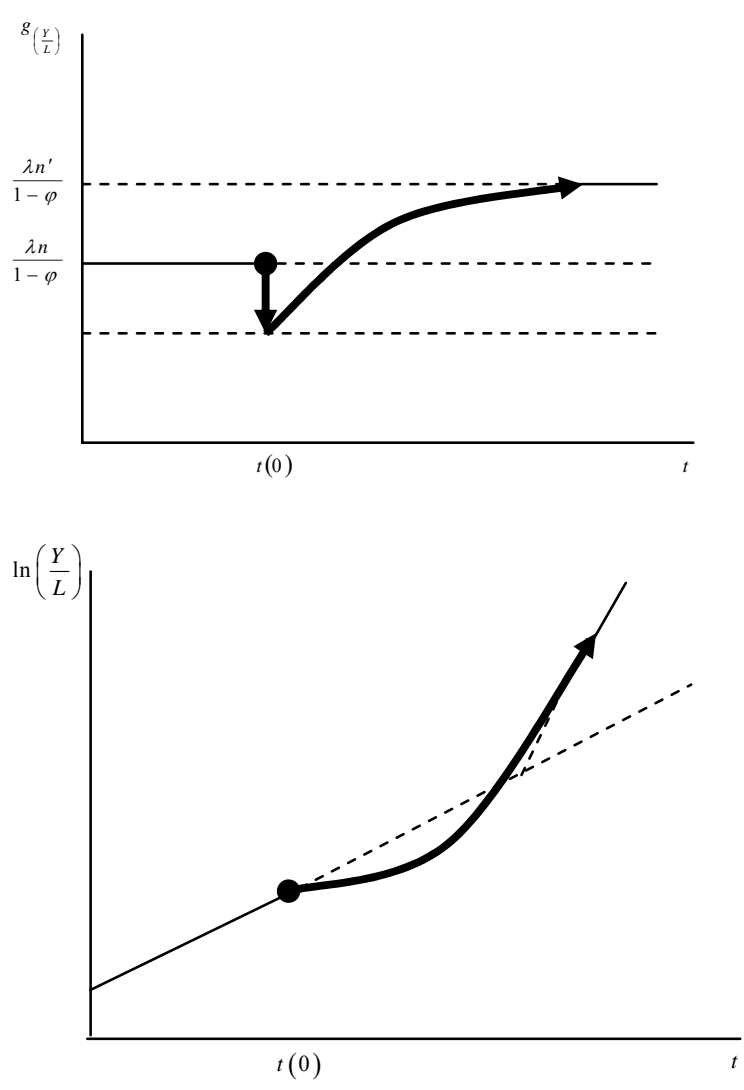
One can now summarize the behaviour of $\ln \left(\frac{Y}{L}\right)$. One knows that due to the falling growth rate directly after the increase in $\mathrm{n}, \ln \left(\frac{Y}{L}\right)$ will become flatter, however as $\mathrm{g}_{\mathrm{A}}$ and $\mathrm{g}_{\mathrm{K}}$ get a chance to react $\ln \left(\frac{Y}{L}\right)$ will start to become steeper again even steeper then the graph was before the increase in $\mathrm{n}$.

I have now reached the last part of iv), and I conclude with commenting on what the "two-step approach" short-cut did not show us at first sight. Looking at the permanent increase in $\mathrm{s}_{\mathrm{R}}$ the "two-step approach" shows where the economy moves when the shock occurs and where it will end up again. Due to the straight fashion with which $g_{K}$ will return to its BGP, nothing is lost in the dynamic process while using our short-cut. Problems arise however when the dynamics are not straight but curved. The other case with a permanent increase in $\delta$ has a curved dynamic adjustment path, and thus only looking at what the "two-step approach" tells us will not show us how the adjustment takes place. The "two-step approach" shows us where we are and where we will go, but due to the interplay between $g_{A}$ and $g_{K}$ the adjustment is not taking place in a straight fashion, instead we have the increase in $\mathrm{g}_{\mathrm{K}}$, and decrease after passing the $\dot{g}_{K}=0$ line, which one might have missed if one had not looked a bit deeper into the dynamics.

\section{v) Balanced Growth Path values of $g_{A}^{*}$ and $g_{K}^{*}$}

In order to show what values $\stackrel{*}{A}_{A}$ and $g_{K}^{*}$ will have once we enter the BGP one requires to make a few assumptions (which are common in several literature on the subject). These assumptions will be used for the remainder of the paper.

$$
n=0.01 \quad \alpha=\frac{1}{3} \quad \lambda=\frac{2}{3} \quad \varphi=\frac{2}{3} \quad \mathrm{~A}(0)=1 \quad \frac{Y(0)}{L(0)}=1
$$

Since I are looking for the balanced growth path of $\dot{g}_{A}^{*}$ and $\dot{g}_{K}^{*}$ I will have to look at where $\dot{g}_{A}=0$ and $\dot{g_{K}}=0$ respectively. Starting with $\dot{g}_{A}^{*}$ :

$\dot{\mathrm{g}}_{\mathrm{A}}(\mathrm{t})=\lambda \mathrm{ng}_{\mathrm{A}}-(1-\varphi) \mathrm{g}_{\mathrm{A}}{ }^{2}=>\mathrm{gg}_{\mathrm{A}}=\lambda \mathrm{n}-(1-\varphi) \mathrm{g}_{\mathrm{A}}$

Inserting the given values and noting $\dot{g}_{A}=0$ at BGP

$0=\frac{2}{3} * 0.01-\left(1-\frac{2}{3}\right) g_{A}^{*}=>\frac{1}{3} g_{A}^{*}=\frac{2}{300} \Rightarrow g_{A}^{*}=0.02$

Now that I have derived the balanced growth path for $g_{A}^{*}$ I can continue to calculate it for $g_{K}^{*}$

$\dot{g_{K}}=(1-\alpha)\left(g_{A}+n-g_{K}\right) g_{K} \Rightarrow g g_{K}=(1-\alpha)\left(g_{A}+n-g_{K}\right)$

Inserting the given values and noting $\dot{g}_{K}=0$ at BGP

$0=\left(1-\frac{1}{3}\right)\left(0.02+0.01-g_{K}^{*}\right) \Rightarrow>0=0.03-g_{K}^{*}=>g_{K}^{*}=0.03$ 
Thus I have now proven that under the current assumptions we have a ${ }_{g_{A}}^{*}=0.02$ and a $\stackrel{*}{*}_{K}=0.03$ along the Balanced Growth Path.

\section{vi) EXCEL-generated shocks}

For this subsection I have developed an EXCEL spreadsheet that will allow to track the consequences of changes in the model parameters for the paths of $g_{A}, g_{K}, \ln A, \ln (Y / L)$ and $g_{Y / L}$. This spreadsheet has seven columns and I take a time horizon of 500 years for the simulations. The shochs occur in year 50 . The first shock examined is a doubling of $s_{K}$ in Year 50. The EXCEL generated plot in $\left(g_{A}, g_{K}\right)$-space is represented below:

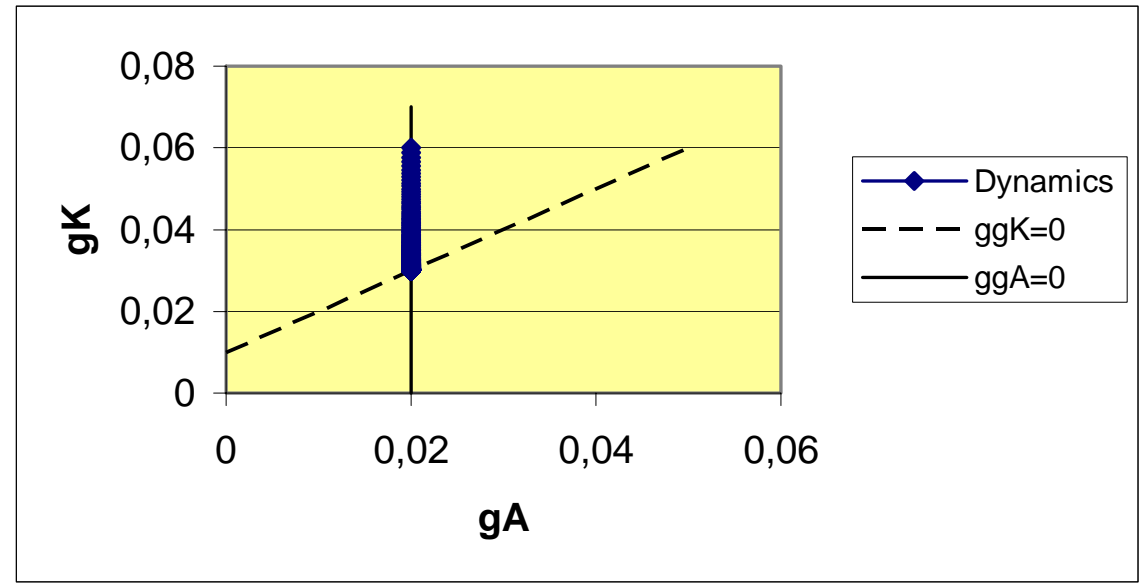

The dynamics of the $s_{K}$ shock are described by the thick line labelled "dynamics". At the moment of the shocks, $g_{K}$ jumps upwards. The fact that we are now above the $\mathrm{gg}_{\mathrm{K}}=0$ line implies that $\mathrm{gg}_{\mathrm{K}}<0$. This is why $\mathrm{g}_{\mathrm{K}}$ after its upward jump decreases again and is dragged back to the steady state. As can be seen from the graph, the dynamics-line becomes compacter as $\mathrm{g}_{\mathrm{K}}$ falls back towards its original level. The thickness means that the fall of $g_{K}$ actually becomes slower the closer $g_{K}$ is to its steady state position, which makes sense, as $\mathrm{gg}_{\mathrm{K}}$ is also closer to zero and the pull becomes weaker.

The following time series diagrams show the level effect of a rise in $s_{K}$ on the level of output per worker, $\ln (\mathrm{Y} / \mathrm{L})$, and on the growth rate of ouput per worker, $\mathrm{g}_{\mathrm{Y} / \mathrm{L}}$. The doubling of $\mathrm{s}_{\mathrm{K}}$ results in a temporarily faster increase in Y/L, thus a jump to a higher level. Due to the dynamics that have been described in the previous $\left(g_{A}, g_{K}\right)$ graph, the growth rate $g_{K}$ (and thus also $g_{Y / L}$ ) is dragged back to its original value. Therefore, we only have a level and not a growth effect. The stock of knowledge A is not at all affected by the increase in $\mathrm{S}_{\mathrm{K}}$ as can be seen from the lowest graphs. There, the $\ln \mathrm{A}$ line before and after the shock are identical. 

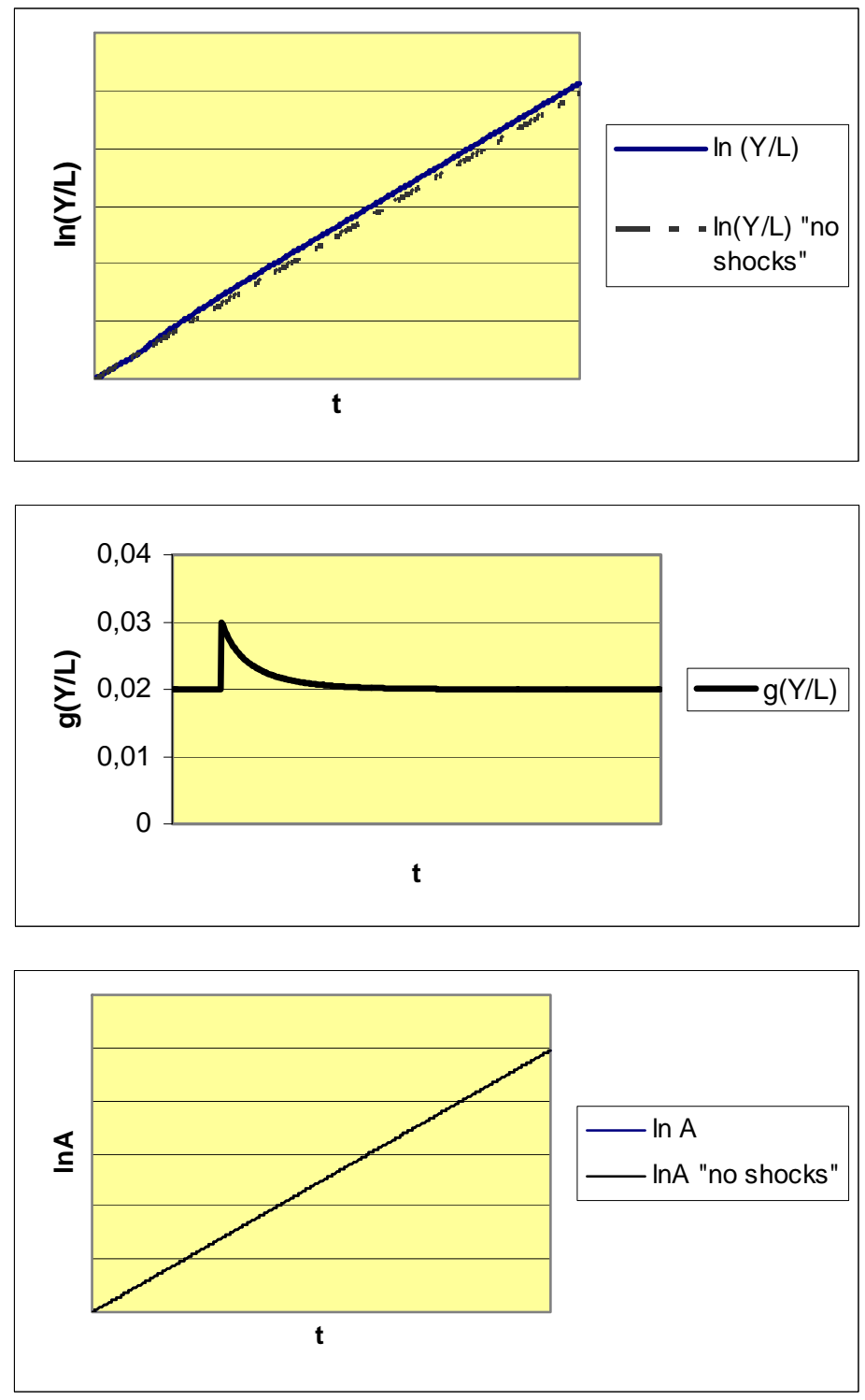

I now turn to the second shock to the model, i.e., a doubling in $\delta$ in Year 50. The increase in $\delta$ results in a jump of $g_{A}$ to the right. Then, the forces of the 'arrows' set in that have been discussed in previous sections. The dynamics imply that $g_{A}$ is being pulled back to the right to its steady-state value following a bow-shaped way.

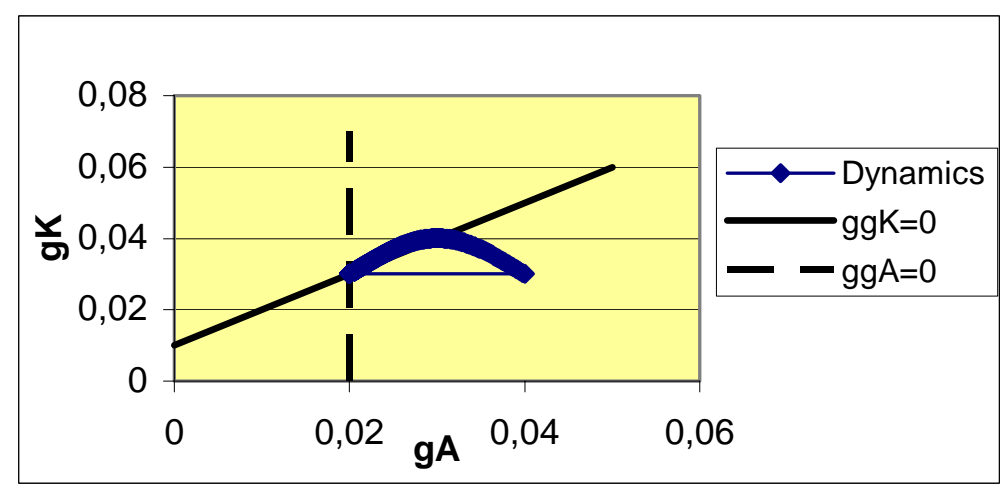


The following time series diagrams show again that a level effect occurred. The rise in $\delta$ cased the level of output per worker and the stock of knowledge A to rise.

The impact on the growth rate of $g_{Y / L}$ that can be seen the third diagram also shows that there was no permanent growth effect. At the moment of the shock, $t=50, g_{Y / L}$ jumps up and then gradually falls back to its old value, precisely the dynamics that are depicted in the $\left(\mathrm{g}_{\mathrm{A}}, \mathrm{g}_{\mathrm{K}}\right)$ graph.
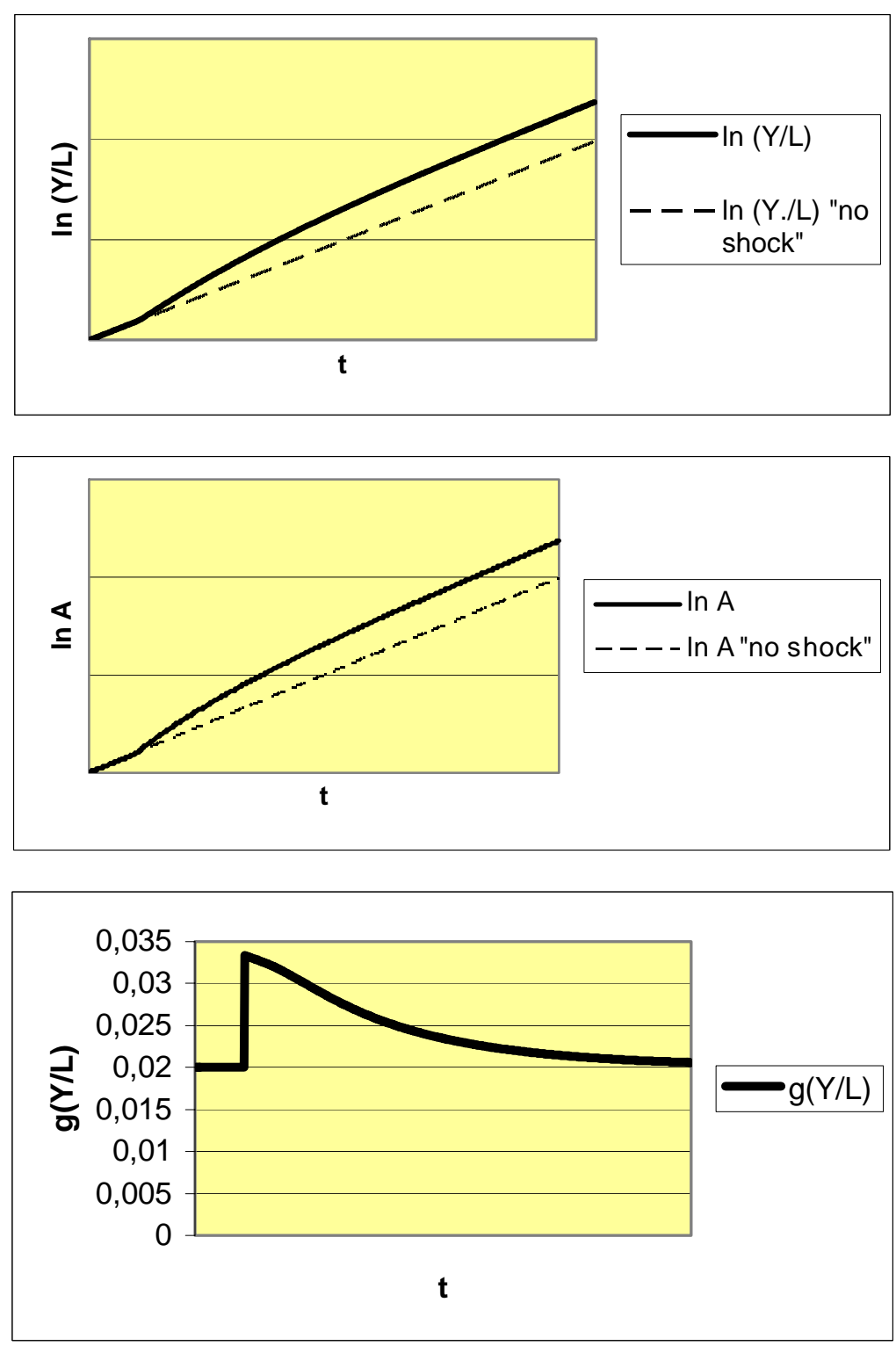

The last shock is a doubling of the population growth rate $\mathrm{n}$ in Year 50. This time, I have a different picture, as we actually have a growth effect. As can be seen in the $\left(\mathrm{g}_{\mathrm{A}}, \mathrm{g}_{\mathrm{K}}\right)$ graph below, as a result of the increase in $n g_{A}$ and $g_{K}$ gradually move to their new, higher steady-state values. There is no jump this time. Talking about magnitudes, we see that in our model the doubling of $n$ also leads to a doubling of $g_{A}$ and $g_{K}$. 


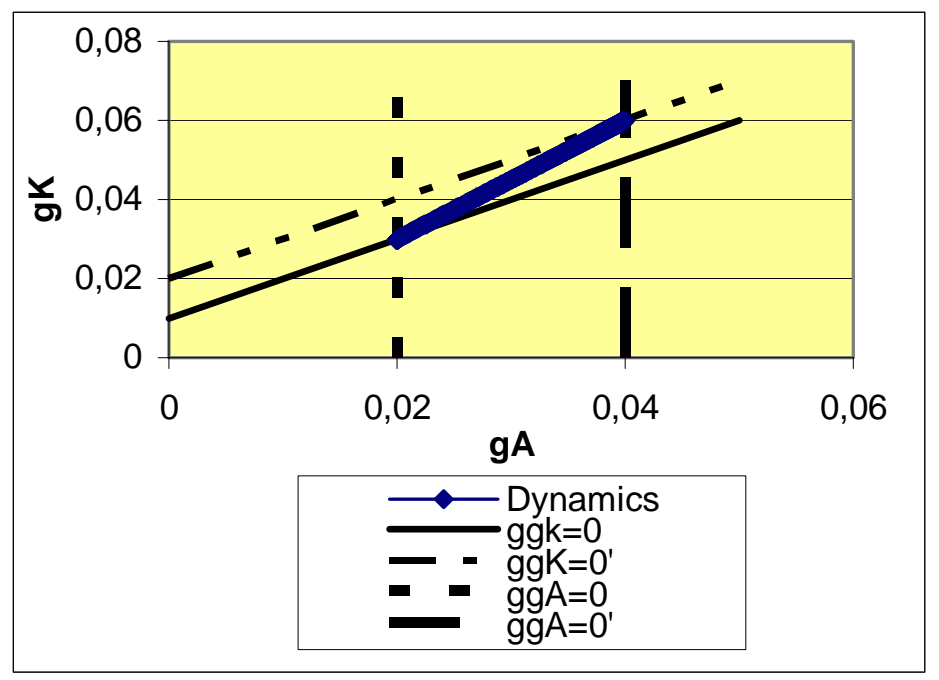

I now consider the time series diagrams. There are a couple of interesting things to observe. First, the ln A graph perfectly reflects the growth effect. The $\ln$ A line shoots off and there is a widening gap between the line that has been affected by the shock and the original path.

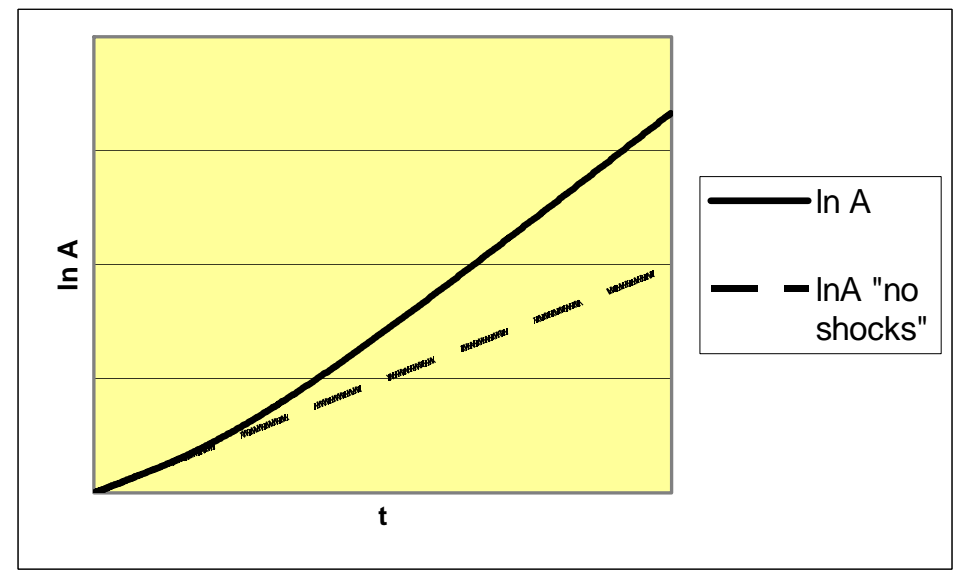

The next diagram depicts the development of the growth rate of output per worker. The increase in $n$ results in an immediate drop of $\mathrm{g}_{\mathrm{Y} / \mathrm{L}}$. This is because at the time the population growth rate increases, $\mathrm{g}_{\mathrm{A}}$ and $g_{K}$ do not immediately follow, there is no jump as has been explained by the $\left(g_{A}, g_{K}\right)$ graph. Thus, $g_{A}$ and $g_{K}$ need some time to get to their new levels. On the way to reaching these higher levels, $g_{\mathrm{Y} / \mathrm{L}}$ rises until it reaches its new, higher value. This temporary drop in $g_{Y / L}$ also explains the last diagram. There we see that due to the drop in $g_{\mathrm{Y} / \mathrm{L}}$ the level of output per worker after the shock is temporarily below the level that would have prevailed had there been no shock. 

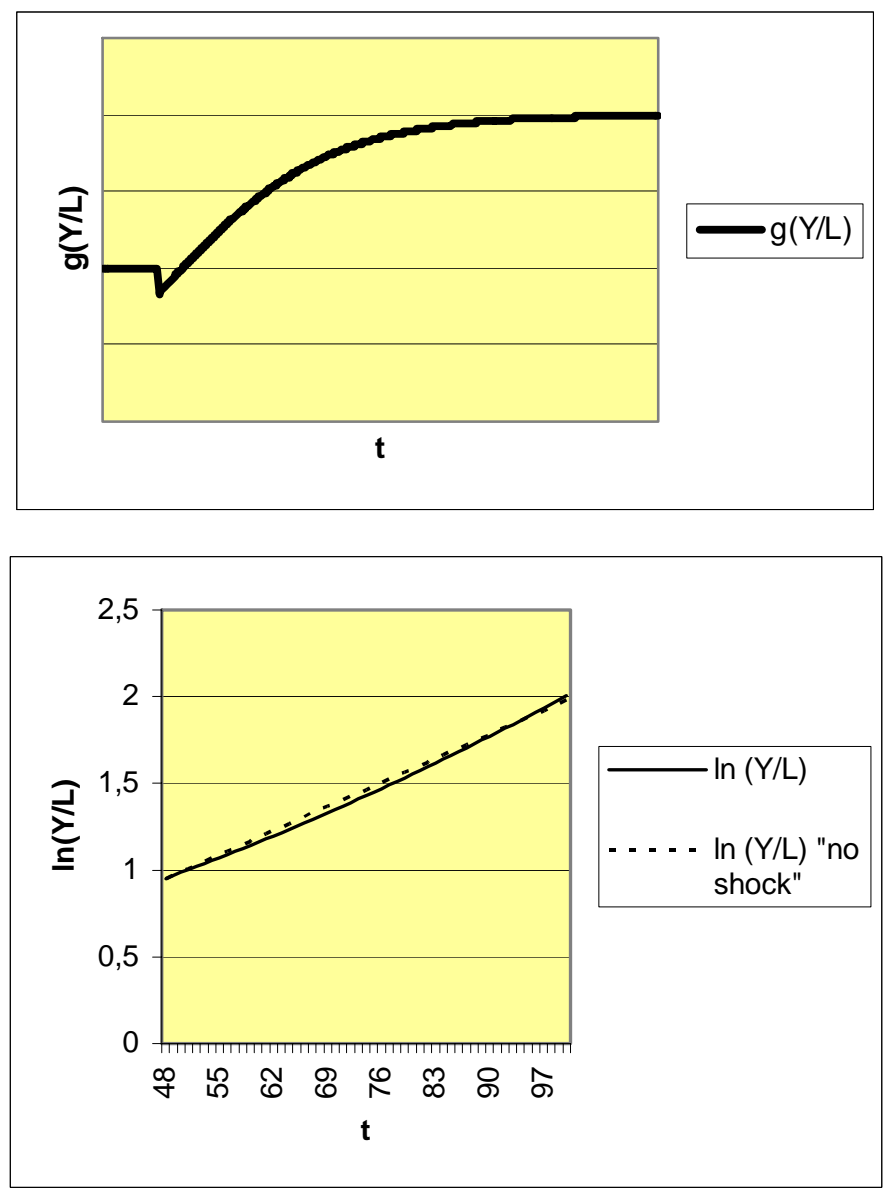

vii) A deeper look

An interesting thing about the $\delta$-shock is the crossing of the $\mathrm{gg}_{\mathrm{K}}$ line as adjustments take place, and that is exactly what we will now look into. After a shock to the economy in the form of a doubling of $\delta$, the economy passes the steady-state line for $\mathrm{g}_{\mathrm{K}}$ between the years 109 and 110 . This can be seen on the spreadsheet when $\mathrm{gg}_{\mathrm{K}}$, which is equal to zero in the steady state, turns negative.

This crossing of the steady-state line of $g_{K}$ by the economy occurs horizontally, which can be explained by the fact that $g_{K}$ crosses the line $g_{g_{K}}=0$. Therefore, on the line itself, $g_{K}$ does neither rise nor fall, but is only moved as $\mathrm{g}_{\mathrm{A}}$ pulls it to the left away from the $\mathrm{gg}_{\mathrm{K}}$ line, thus it crosses horizontally.

Also the $\mathrm{n}$-shock has a few points of interest that will be discussed next. In the steady state, $\mathrm{g}_{\mathrm{Y} / \mathrm{L}}$ has a value of 0.02. After an immediate drop of $g_{Y / L}$ due to a doubling of $n, g_{Y / L}$ first exceeds its baseline value, namely 0.02 , in year 72 . Y/L first exceeds its baseline value in year 94,44 years after the shock. Looking back at the Solow model we know that an increase in the population growth rate will deteriorate the growth of income per head. However the model that we have now analyzed is extended with features that augment it into adding a positive factor to the rise in $\mathrm{n}$. the additions relative to the Solow model allow $\mathrm{n}$ to increase $\mathrm{g}_{\mathrm{A}}$ over time, which increases $\mathrm{g}_{\mathrm{K}}$ over time, and will thus mean Icreate more growth due to the extension. So instead of just the Solow model result I have the drop as suggested by Solow but the Jones extensions create an affect that in the end will create a higher $\mathrm{g}_{\mathrm{Y} / \mathrm{L}}$.

I will now compare the conversion speed between the model economy and the value estimated in section A) ii) . In year $133, \mathrm{~g}_{\mathrm{A}}$ is halfway between the value 0.020133 , its lowest value that it acquired 
immediately after the shock in year 50, and its new steady-state value of 0.04 . The value halfway is 0.0300665 , and in year $133 \mathrm{~g}_{\mathrm{A}}$ has a value of 0.0300665 . When using the formula for a half-life value suggested by Jones

$$
\ln 2 / \lambda^{\circ}=\text { half-life value }=>\ln 2 /(133-50)=\lambda^{\circ}=0.00835
$$

I obtain a convergence speed of 0.00835 as opposed to the convergence speed of 0.0133 obtained in part Aii). Taking into consideration the Taylor logic that the approximation should perform increasingly better the closer I get to the steady-state, I take a look at the convergence speed at a half-life value between the value of $g_{A}$ in year 133 and 0.04 . This half-life value of 0.035003325 is obtained in the Excel model in year 196 (exact value for $\mathrm{g}_{\mathrm{A}}$ in year $196=0.0350027$ ).

$$
\ln 2 /(196-133)=0.0110023
$$

The new convergence speed of 0.011 is clearly closer to 0.0133 of part Aii) than the previous value of 0.00835 . Therefore, the Taylor logic holds and the predicted convergence speed and the one we derived converge the closer I get to the steady state. 


\section{References}

- GROSSMAN, G.M., HELPMAN, E., [1991], Innovation and Growth in the Global Economy, CMIT Press, Cambridge, MA

- JONES, C.I. [2002], Introduction to Economic Growth, $2^{\text {nd }}$ edition, WW Norton\&Company.

- LUCAS, Robert E., Jr. [1988], On the mechanics of economic development, Journal of Monetary Economics 22 (July): 3-42

- KLENOW, P., RODRIGUEZ-CLARE, A. [1997], Economic Growth - A Review Essay, Journal of Monetary Economics, 40, 597-617

- $\quad$ SALA-I-MARTIN, X. [1996], The classical approach to convergence analysis, $1^{\text {st }}$ edition, The Economic Journal, Vol.106, pp 1019-1036.

- ROMER, D. [1990], Endogenous Technological Change, Journal of Political Economy, 98(5), S71-S102

- $\quad$ ROMER, David [2001], Advanced Macroeoconimcs, $2^{\text {nd }}$ Edition, McGraw-Hill.

- $\quad$ SYDSAETER, K, HAMMOND, P., [2002], Essential mathematics for economic analysis, $1^{\text {st }}$ edition, Harlow UK, Financial Times/Prentice Hall.

- WOOLDRIDGE, J.M. [2002], Introductory Econometrics: a modern approach, $2^{\text {nd }}$ edition, Thomson South Western. 